\begin{abstract}
Iranica
Abstracta Iranica Revue bibliographique pour le domaine irano-aryen

Volume 34-35-36 | 2017

Comptes rendus des publications de 2011-2013
\end{abstract}

\title{
Bruce Wannell, Wahid Amini. Herat Elite Burials. An endangered heritage.
}

Sandra Aube

\section{OpenEdition}

Édition électronique

URL : http://journals.openedition.org/abstractairanica/41247

DOI : 10.4000/abstractairanica.41247

ISSN : 1961-960X

Éditeur :

CNRS (UMR 7528 Mondes iraniens et indiens), Éditions de l'IFRI

\section{Référence électronique}

Sandra Aube, «Bruce Wannell, Wahid Amini. Herat Elite Burials. An endangered heritage. », Abstracta Iranica [En ligne], Volume 34-35-36 | 2017, document 5, mis en ligne le 15 juillet 2016, consulté le 26 septembre 2020. URL : http://journals.openedition.org/abstractairanica/41247 ; DOI : https://doi.org/ 10.4000/abstractairanica.41247

Ce document a été généré automatiquement le 26 septembre 2020.

Tous droits réservés 


\title{
Bruce Wannell, Wahid Amini. Herat Elite Burials. An endangered heritage.
}

\author{
Sandra Aube
}

\section{RÉFÉRENCE}

Bruce Wannell, Wahid Amini. Herat Elite Burials. An endangered heritage. Kaboul, Aga

Khan Trust for Culture, 2013, 228 p., ill. couleur, anglais et dari.

1 Ce livre propose un catalogue de tombes en pierre sculptée (stèles ou cénotaphes) à décor épigraphique conservées à Hérat. Ce recensement est le résultat d'une étude menée entre 2007 et 2008 par des architectes sous l'égide de l'Aga Khan Trust for Culture : il s'agissait alors d'enregistrer les tombes conservées dans la cour principale du mausolée timouride de 'Abdollāh Anșāiñ à Gāzorgāh (Hérat, 832/1428-1429). Pour cette publication, le survey a été complété par l'adjonction d'autres tombes conservées dans les autres espaces du mausolée. Le catalogue comprend ainsi un total de 31 entrées.

2 Chaque entrée propose d'abord une présentation de la tombe étudiée, d'une grande brièveté et sans ancrage bibliographique. Mais l'intérêt de l'ouvrage réside principalement dans toutes les inscriptions des tombes qui ont été lues et transcrites en persan. Elles sont généralement accompagnées de photographies de bonne qualité, permettant de vérifier au besoin les transcriptions. Ces dernières ne sont toutefois pas traduites en anglais. Ponctuellement, des relevés des décors ont été proposés.

3 Ces tombes sont classées par ordre chronologique. Le livre commence ainsi par un premier ensemble de 13 ensembles de tombes relevant des périodes timouride et safavide (chapitre 1, p. 10-103). Suit un chapitre rassemblant 10 ensembles d'inscriptions funéraires chingizides (p. 104-145), puis une dernière partie consacrée à 8 ensembles non datés (p. 146-183).

4 Ce catalogue est suivi d'une série d'annexes. L'annexe A («Oral History») est un morceau-choisi de deux interviews: celle d'un imam sur l'évolution des pratiques 
autour du culte des tombes, puis d'un fossoyeur sur sa pratique professionnelle. Suit un index (annexe B), un glossaire (C), des clés d'interprétation des dates en abjad (D), un tableau méthodologique pour l'enregistrement des tombes $(\mathrm{E})$, une liste des prières et versets coraniques utilisés (F), des poèmes persans employés ( $G$, en persan uniquement), puis des références historiques persanes ( $\mathrm{H}$, en persan seulement).

Les AA. ont voulu inscrire leur étude dans la lignée de l'importante monographie menée sur le site par Lisa Golombek en 1968 (PhD soutenue en 1968 et publiée en 1969 par le Royal Ontario Museum sous le titre: The Timurid Shrine at Gazur Gah). Si le livre que proposent Bruce Wannell et Wahid Amini ne présente certainement pas une telle envergure, il s'avère constituer un outil utile pour la communauté scientifique, qui y trouvera un catalogue de ressources nouvelles.

\section{AUTEURS}

\section{SANDRA AUBE}

CNRS, Mondes iranien et indien, Paris 